plans for a hospital with 2,500 beds, in which every conceivable specialty and subspecialty was to be represented. By its mere dimensions the control of such a hospital will pass out of the hands of the doctors, who will be reduced to technical specialists, each in his own narrow field. The individual at all levels is thus reduced in importance ; and this is equally true of patient and physician. The attitudes become group-centred, rather than individual-centred. To work with rer onable efficiency in such a place a new type of doctor may 1 , required, one who is satisfied with an anonymous group-ego within the medical unit. Again I can see no easy way to mould the bright, curious, and enterprising medical student into such a shape, although I must admit that in our school system there are obvious tendencies to promote this development.

What else is going to happen in the community ? It seems as if people will continue to agglomerate in cities and large towns-whenever necessary spreading out again into adjacent suburbs. There is little hope that in the next ten years we shall see an end to the shortage of good urban housing or to the ensuing traffic congestion. There may be an increased tendency, with a greater amount of leisure time, for more people to indulge in double housing. In contrast to road-bound traffic, wireless communication seems to be without limits.

All this will probably result in an infinitely more complicated and interlocked society, depending more and more on internal regulations to diminish friction. Teachers and doctors together will be given the task of conditioning citizens to this regulation of human nature. The task of manipulating their fellow-men, by means of drugs, neurophysiological conditioning, and social casework, will ultimately become a major one for the future general practitioner and his para-medical collaborators. The pharmaceutical industry will certainly help to pave the way for the brave new world.

\section{Conclusion}

I have already said that I believe there is more than fiction to medical science fiction. The Brave New World and the Oceania of 1984 are representations of the anxiety and horror experienced by British liberals before the advancing social technology. I am afraid there is more to this kind of fiction. It may well represent what we all are up against, not necessarily from political evil, but from the inherent course of technology as such. For a long time Britain has stood as a safeguard of individualism, of freedom, and of independence-so much so that you have given these values priority to short-sighted material gains. But the question is, for how long will you be able to avoid a more definite break-through of tendencies prevailing in many other parts of the world, including mine? From a speech by the Chief Medical Officer to the Ministry of Health, Sir George Godber, I conclude that more hospitals, more group-practices, and less individual medicine will be the Ministry's keynotes, and they sound very familiar to me. Apparently we are all bound for a new era, that of "greater medicine." Let us hope that this will be not only a quantitative goal. If it has to come, we must try to make it truly great.

\title{
Effectiveness of Pertussis Vaccines
}

\author{
NOEL W. PRESTON,* M.D., DIP.BACT., M.C.PATH.
}

Brit. med. F., 1965, 2, 11-13

As the result of a preliminary study (Preston, 1963) it was suggested tentatively that pertussis vaccines may be providing children with incomplete immunity against some strains of Bordetella pertussis. The need was stressed for a fuller investigation of freshly isolated strains, and comparison of their antigenic composition with that of pertussis vaccines. With the ready co-operation of many general practitioners, paediatricians, and bacteriologists throughout the country, a widespread collection of material has now provided sufficient evidence to confirm this tentative suggestion beyond reasonable doubt.

\section{Materials and Methods}

Strains.-Strains of Bord. pertussis were obtained from the Public Health Laboratories in Bournemouth, Brighton, Bristol, Cardiff, Coventry, Ipswich, Leeds, London (Colindale), Manchester, Southend, and Swansea ; Ruchill Hospital, Glasgow ; Fazackerley and Alder Hey Hospitals, Liverpool; Lambeth Hospital, London; Ancoats, Booth Hall, Duchess of York, Monsall, and Withington Hospitals, Manchester ; Royal Manchester Children's Hospital ; Hope Hospital, Salford ; Western Bank Children's Hospital and the University, Sheffield; and from home cases in Manchester, Salford, and Wigan.

Typing Sera.-The three major heat-labile agglutinogens (1, 2 , and 3) of Bord. pertussis were originally described by Andersen (1953), antigen 1 being species-specific-that is, common to all strains of Bord. pertussis-and antigens 2 and 3 being type-specific-that is, present either alone or together on

* Senior Lecturer, Depariment of Bacteriolozy, University of Manchester. different strains of the species. Monospecific absorbed antisera for these three antigens have been prepared and standardized as previously described (Preston and Te Punga, 1959; Preston 1963).

Serological Typing by Slide-agglutination.-A suspension of each strain of Bord. pertussis, grown on charcoal-blood-agar, and each vaccine (standardized to contain approximately 50,000 million organisms per ml.) was mixed with a standard loopful of each of the three monospecific sera on a glass slide and rocked gently for five minutes. If there was then no apparent agglutination by antibody 1, observation was continued for a further five minutes. Degrees of agglutination were recorded as follows :

$$
\begin{aligned}
& +++ \text {, Rapid agglutination, complete within } 3 \text { minutes. } \\
& ++ \text {, Agglutination within } 3 \text { minutes; complete within } 5 \\
& \text { minutes. } \\
& + \text {, Slow agglutination, incomplete within } 5 \text { minutes. } \\
& \pm \text {, Very slow agglutination, inapparent within } 5 \text { minutes, } \\
& \text { incomplete within } 10 \text { minutes. } \\
& \text { 0, No agglutination (by antibody } 2 \text { or } 3 \text { ) visible to naked eye } \\
& \text { within } 5 \text { minutes. }
\end{aligned}
$$

\section{Typing of Strains}

From January 1963 to December 1964155 freshly isolated strains of Bord. pertussis were collected from cases of whoopingcough occurring in widely separated areas of Great Britain : 132 $(85 \%)$ were agglutinated only by antibodies 1 and 3 (serotype $1,3), 2(1 \%)$ by antibodies 1 and 2 (serotype 1,2), and 21 $(14 \%)$ by all three antibodies (serotype $1,2,3)$. The predomi- 
nance of type 1,3 strains applied to each locality, as shown in Table I ; and it did not alter significantly during the two years (Table II).

TABLE I.-Serotypes of Bord. pertussis Isolated in Great Britain in 1963-4. Geographical Distribution

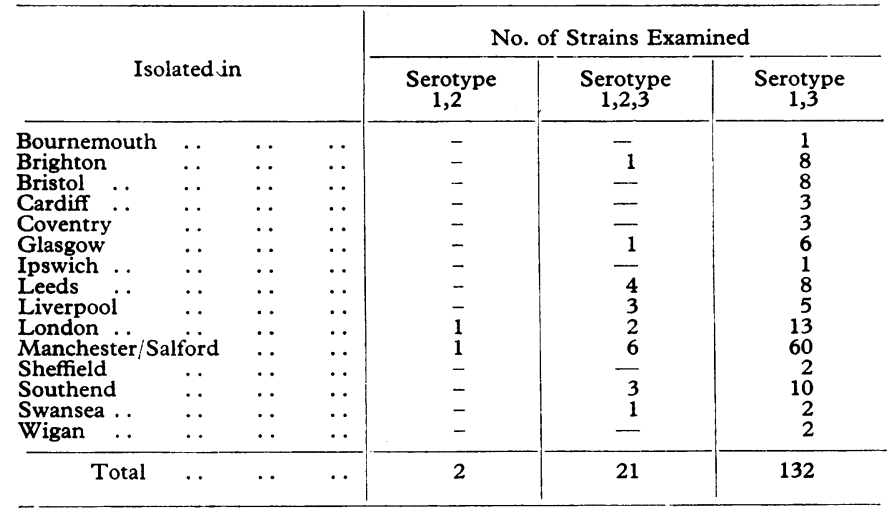

TABLE II.-Serotypes of Bord. pertussis Isolated in Great Britain in 1963-4. Chronological Distribution

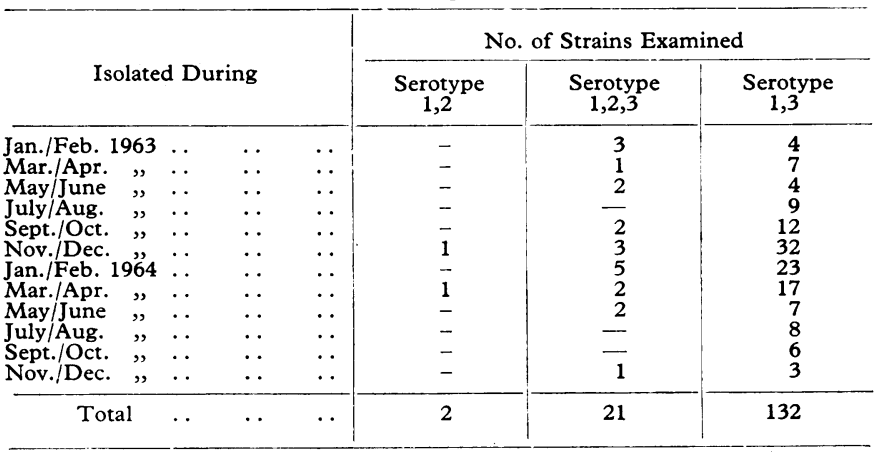

However, there was a clear relationship between the vaccination history of the patient and the serotype of the infecting strain (Table III). Type 1,2 or type $1,2,3$ strains were isolated only from unvaccinated patients, whereas type 1,3 strains were isolated from both vaccinated and unvaccinated. So marked was this distinction that it became possible to predict that a type 1,2 or type $1,2,3$ strain would have been obtained from an unvaccinated patient. Indeed, three children who were infected with type 1,2,3 strains and who were stated to have been vaccinated, were shown on examination of medical records to have received either no pertussis vaccine at all or, an incomplete primary course.

TABLE III.-Relation Between Vaccination History of Patient and
Serotype of Infecting Strain of Bord. pertussis

\begin{tabular}{|c|c|c|c|c|c|c|}
\hline \multirow{2}{*}{\multicolumn{4}{|c|}{ Vaccination History }} & \multicolumn{3}{|c|}{ Serotype } \\
\hline & & & & \multirow{2}{*}{$\frac{1,2}{2}$} & \multirow{2}{*}{$\frac{1,2,3}{\overline{21}}$} & \multirow{2}{*}{$\begin{array}{r}1,3 \\
23 \\
99 \\
10\end{array}$} \\
\hline $\begin{array}{l}\text { Vaccinated } \\
\text { Unvaccinated } \\
\text { Not known }\end{array}$ & $\begin{array}{l}\ldots \\
\cdots\end{array}$ & $\begin{array}{l}\cdots \\
\therefore\end{array}$ & $\begin{array}{l}\cdots \\
\cdots \\
\cdots\end{array}$ & & & \\
\hline Total & $\cdots$ & $\ldots$ & . & 2 & 21 & 132 \\
\hline
\end{tabular}

Vaccination = Complete primary course of three injections of pertussis vaccine or of combined antigen including pertussis vaccine.

About half of the 65 patients from whom a clinical assessment was obtained had only mild infections, whether with type 1,3 or type $1,2,3$ strains. However, $11(17 \%)$ of the infections were severe, four of them fatal. All four deaths were caused by infection with type 1,3 strains in babies under 3 months of age. Although the vast majority of all cases were children, the patients with mild infections included seven older ones with ages ranging from 18 to 60 years, six of whom were infected with type 1,3 strains.

Table IV gives detailed results of the serological typing of strains by agglutination with monospecific antisera. Attention is drawn particularly to the 23 strains of serotype 1,3 which were agglutinated only very slowly $( \pm)$ by antibody 1 . Such strains were first isolated in November 1963 ; during the first half of 1964 they constituted $10(18 \%)$ of the 57 strains examined; during the latter half of 1964 they constituted 9 $(50 \%)$ of the 18 strains examined. Although agglutinating so poorly with antibody 1 , most of these strains were strongly agglutinated $(++$ or +++$)$ by antibody 3 , and they formed a gradually increasing proportion of all the freshly isolated strains that were examined during the two years.

TABLE IV.-Details of Serological Typing of Strains of Bord. pertussis

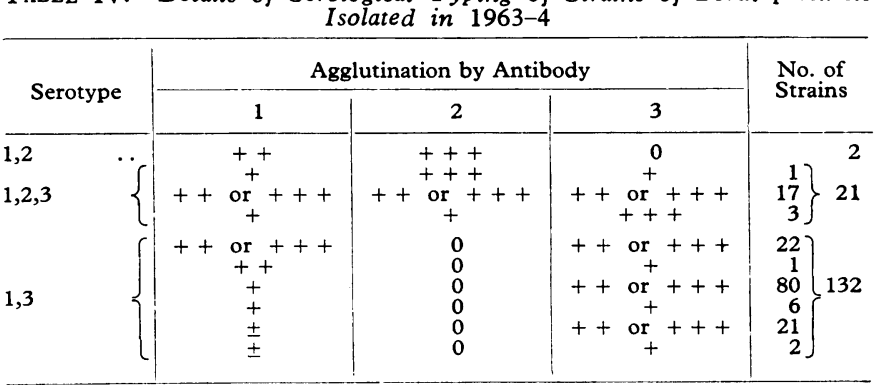

For significance of degrees of agglutination see text.

\section{Antigenic Content of Vaccines}

Material from three British manufacturers, either in the form of vaccine currently used for the immunization of children in this country or strains used in the manufacture of such vaccine in 1963, was tested by slide-agglutination with monospecific antisera (Table V). With the exception of one vaccine strain, antigen 3 was not detected in any of this material. Clearly, many children in this country are receiving vaccines prepared from strains containing antigens 1 and 2 but not 3 .

\begin{tabular}{|c|c|c|c|c|c|}
\hline \multirow{2}{*}{ Manufacturer } & \multirow{2}{*}{$\begin{array}{l}\text { Strain } \\
\text { of Per- } \\
\text { tussis }\end{array}$} & \multirow{2}{*}{$\begin{array}{c}\text { Batch of } \\
\text { Pertussis } \\
\text { Vaccine } \\
\text { (Date of } \\
\text { Manufacture) }\end{array}$} & \multicolumn{3}{|c|}{ Agglutination by Antibody } \\
\hline & & & 1 & 2 & 3 \\
\hline $\mathbf{P}$ & $\begin{array}{l}23 \\
29 \\
34\end{array}$ & & $\begin{array}{l}+++ \\
+++ \\
+++\end{array}$ & $\begin{array}{l}+++ \\
+++ \\
+++\end{array}$ & $\begin{array}{l}0 \\
0 \\
0\end{array}$ \\
\hline Q & $\begin{array}{l}21 \\
31 \\
41\end{array}$ & & $\begin{array}{l}+++ \\
+++ \\
+++\end{array}$ & $\begin{array}{l}+++ \\
+++ \\
+++\end{array}$ & $+\underset{0}{+}+\underset{+}{+}$ \\
\hline $\mathbf{R}$ & & $\begin{array}{l}\text { Aug. } 1963 . \\
\text { Oct. } 1963 \\
\text { Dec. } 1963 \\
\text { Feb. } 1964 \\
\text { July } 1964\end{array}$ & $\begin{array}{c}+++ \\
++ \\
++ \\
+ \\
+\end{array}$ & $\begin{array}{c}+++ \\
++ \\
++ \\
+ \\
+\end{array}$ & $\begin{array}{l}0 \\
0 \\
0 \\
0 \\
0\end{array}$ \\
\hline
\end{tabular}

\section{Discussion}

Before 1958 most of the pertussis infections in this country were caused by strains of type 1,2, and less frequently of type 1,2,3 (Preston, 1963) ; type 1,3 was rare. British vaccines in 1955 were made predominantly from type 1,2 strains and seldom contained antigen 3 (Preston, 1963). The same is true of recently manufactured vaccine (Table $\mathrm{V}$ ).

The virtual disappearance of type 1,2 strains from the community by 1963 (Tables I, II) testifies to the efficacy of these vaccines. Moreover, they seem to give good protection against type 1,2,3 infection, which now occurs only in unvaccinated patients, but not against type 1,3 strains (Table III).

After the introduction of pertussis vaccine there was a fairly steady decline in the incidence of whooping-cough until 1962, when the notification rate was the lowest on record (Report, 1965). However, there was a marked increase in notifications in 1963-4, most of the infections being caused by type 1,3 strains. This was probably a selective proliferation of type 1,3 organisms 
in a population of children who were largely immune, by vaccination, to type 1,2 and type 1,2,3 infection. Evidence is here presented (Table IV and accompanying text) to suggest that a further process of selection is occurring: type 1,3 strains isolated in 1963 were readily agglutinated by both antibodies (1 and 3); but during 1964 an increasing proportion were agglutinated very poorly by antibody 1 and appeared to have only one major agglutinogen (antigen 3 ). Thus organisms which produce antigens 1 and 2 as major components are apparently being eradicated by efficient vaccines in which these two antigens are well represented, while strains in which antigen 3 is the major component are able to flourish in the vaccinated community.

There is therefore an immediate need to modify the pertussis vaccines used in this country so that they contain strains in which all three antigens are adequately represented; and it is reasonable to believe that such modified vaccines would protect against pertussis infections caused by all three serotypes. It is important, however, that checks be made from time to time on the antigenic nature of strains isolated, especially from vaccinated persons, so that, if this modification of the vaccines should cause the emergence of yet another serotype as the predominant form of the organism, appropriate adjustments may be made in the strain-composition and testing of vaccines.

The present mode of assay, in testing the potency of pertussis vaccine, is clearly inadequate. Batches of vaccine which are rich in antigens 1 and 2 will readily pass the test, though they give children incomplete protection against current infecting strains. The need for a different form of potency test is discussed elsewhere (Preston, in press).

\section{Summary}

Eleven British pertussis vaccines and vaccine strains in current use have been examined serologically by slide- agglutination with monospecific pertussis antisera. All contained antigens 1 and 2, but antigen 3 was found in only one of them.

So effective are these vaccines that type 1,2 strains of Bordetella pertussis have been virtually eliminated in this country. Vaccination gives adequate protection also against type 1,2,3 strains, which in 1963-4 have been isolated only from unvaccinated patients. Type 1,3 strains, however, have infected both vaccinated and unvaccinated people, and have constituted $132(85 \%)$ of the 155 strains examined.

Of the type 1,3 strains isolated during 1964 an increasing proportion have been very poorly agglutinated by antibody 1 , though they were still agglutinated readily by antibody 3 . These strains constitute a new subtype against which vaccines containing only antigens 1 and 2 could not be expected to immunize.

There is an urgent need for the modification of pertussis vaccine so that it shall contain strains in which all three antigens are adequately represented.

This investigation was undertaken only with the ready co-operation of medical practitioners, scientific officers, and technicians, whose help and assistance are gratefully acknowledged-namely; Dr. J. W. Howie and the staff of the Public Health Laboratory Service; paediatricians and general practitioners in Manchester, Salford, and Wigan; the clinical and laboratory staff of the hospitals named in the text ; and the technical staff of this department.

\section{REFERENCES}

Andersen, E. K. (1953). Acta path. microbiol. scand., 33, 202 Preston, N. W. (1963). Brit. med. F., 2, 724 Preston, Path. Bact. In press.

and Te Punga, W. A. (1959). Ibid., 78, 209.

Report: Public Health Laboratory, Manchester; City of Manchester Health Department ; Department of Bacteriology, University of Manchester (1965). Mth. Bull. Minist. Hlth Lab. Serv., 24, 104.

\title{
Studies on Killed and Attenuated Measles Vaccines in General Practice
}

\author{
G. I. WATSON,* M.D., M.C.G.P.
}

Brit. med. F., 1965, 2, 13-16

The best way to prevent measles is still being sought. Attenuated measles virus vaccines, mainly derived from the Edmonston strain (Enders and Peebles, 1954), have been shown to confer substantial protection against the natural disease (Katz and Enders, 1959 ; Aldous et al., 1961 ; Katz et al., 1962; Goffe et al., 1963 ; Krugman et al., 1965), but these vaccines also produced varying degrees of fever and rash. Further attenuation of such vaccines has reduced but not yet abolished these adverse reactions (Schwarz, 1962 ; Hendrickse et al., 1964), and may diminish the antibody response (Benson et al., 1964). Meanwhile killed vaccines have been developed which evoke little or no adverse clinical reaction (Karelitz, 1963) but are less certain in their protection (Lipschutz et al., 1962).

A concurrent dose of gamma-globulin has been used to reduce or abolish the adverse clinical reactions to attenuated vaccines (Stokes et al., 1961), as well as in attempts to modify or prevent measles among contacts (Krugman et al., 1962). Fever and rash after attenuated vaccines have also been reduced by giving up to three doses of a killed vaccine at monthly intervals before live vaccine is injected (Karelitz and Peck, 1962 ; Guinee, 1963). This method has usually led to higher post-vaccination neutralizing antibody titres than when attenuated vaccine alone is given (Karelitz et al., 1963), but the reverse occurred in a recent trial among children aged 10-18 months (Measles Vaccines Committee, 1965).

Most studies on measles vaccines have been made in the United States. No report has been found dealing specifically with the influence of age on clinical and serological responses. A small number of serological results examined by Mr. G. J. Knight (personal communication, 1964) suggested that up to the age of 2 years "increasing age at vaccination is associated with an enhanced response to measles vaccination." No report has been published about the use in children over 2 years of killed vaccine for modifying adverse reactions to live attenuated vaccines made in Britain.

* General Practitioner, Peaslake, Surrey. 